\title{
The Rate of Cocaine Administration Alters Gene Regulation and Behavioral Plasticity: Implications for Addiction
}

\author{
Anne-Noël Samaha, ${ }^{1}$ Nicolas Mallet, ${ }^{2}$ Susan M. Ferguson, ${ }^{1}$ François Gonon, ${ }^{2}$ and Terry E. Robinson ${ }^{1}$ \\ ${ }^{1}$ Department of Psychology (Biopsychology Program), University of Michigan, Ann Arbor, Michigan 48109-1109, and ${ }^{2}$ Centre National de la Recherche \\ Scientifique Unité Mixte de Recherche 5541, Université Victor Segalen, 33077 Bordeaux, France
}

The rapid delivery of drugs of abuse to the brain is thought to promote addiction, but why this occurs is unknown. In the present study, we characterized the influence of rate of intravenous cocaine infusion (5-100 sec) on three effects thought to contribute to its addiction liability: its ability to block dopamine (DA) uptake, to activate immediate early gene expression, and to produce psychomotor sensitization. Rapid infusions potentiated the ability of cocaine to block DA reuptake, to induce c-fos and $\operatorname{arc} \mathrm{mRNA}$ expression, especially in mesocorticolimbic regions, and to produce psychomotor sensitization. Thus, the rate at which cocaine is delivered influences both its neurobiological impact and its ability to induce a form of drug experience-dependent plasticity implicated in addiction. We propose that rapidly delivered cocaine may be more addictive, in part, because this more readily induces forms of neurobehavioral plasticity that lead to the compulsive pursuit of drugs.

Key words: psychomotor sensitization; intravenous; rate of infusion; immediate early gene; dopamine reuptake-inhibition; rat

\section{Introduction}

A fundamental question in addiction research concerns why some individuals undergo a transition from periodic recreational or circumstantial drug use to the compulsive patterns of drugseeking and drug-taking behavior and propensity to relapse, which characterize addiction. Much research on factors that promote the transition to addiction has focused on genetic, hormonal, or other biological factors that contribute to individual variation in responsiveness to potentially addictive drugs (Piazza et al., 1998). However, some characteristics of drugs themselves may contribute to the propensity to addiction. Indeed, it is widely accepted that drugs, formulations, or routes of administration that result in the rapid entry of a drug into the brain are potentially the most addictive (Gossop et al., 1992, 1994; Winger et al., 1992; Hatsukami and Fischman, 1996). Therefore, it is surprising that there has been almost no research on how the rate of drug delivery alters the neurobiological impact of drugs (cf., Porrino, 1993).

The ability of drugs of abuse to induce a complex pattern of immediate early gene (IEG) expression is thought to be an initial step in their ability to alter synaptic organization and produce persistent forms of neurobehavioral plasticity that contribute to addiction (Hyman and Malenka, 2001; Nestler, 2001). For example, repeated exposure to a variety of drugs of abuse alters synap-

Received March 31, 2004; revised June 1, 2004; accepted June 1, 2004.

This work was supported by National Institute on Drug Abuse (NIDA) Grants R37 DA04294 and K05 DA00473 (T.E.R.). A.-N.S. was supported by an NIDA Institutional National Research Service Award (NRSA) (T32 DA 07267), and S.M.F. was supported by an NIDA Individual NRSA (F31 DA14737). We are grateful to Dr. Pengwei Yang, Dr. Yilin Li, Wendy Yau, and Patrick Castell for expert technical assistance and Dr. Jill B. Venton for helpful discussions.

Correspondence should be addressed to Dr. Terry E. Robinson, Department of Psychology, University of Michigan, East Hall, 525 East University, Ann Arbor, Ml 48109-1109. E-mail: ter@umich.edu.

DOI:10.1523/JNEUROSCI.1205-04.2004

Copyright $\odot 2004$ Society for Neuroscience $\quad$ 0270-6474/04/246362-09\$15.00/0 tic organization in brain regions involved in incentive motivation and reward (such as the striatum), as well as brain regions involved in judgment and the inhibitory control of behavior (such as the prefrontal cortex) (Jentsch and Taylor, 1999; Robinson and Berridge, 2003). Some of these drug-induced adaptations produce behavioral sensitization and facilitate the pursuit of drugs, effects that have been implicated in the transition to addiction (Robinson and Berridge, 2003). We hypothesized, therefore, that varying the rate of cocaine delivery may influence its ability to induce gene expression in mesocorticolimbic structures and to produce behavioral sensitization. We tested this hypothesis in the present study by investigating the effects of the rate of intravenous cocaine administration (from 5 to $100 \mathrm{sec}$ ) on its ability to induce psychomotor sensitization, to induce the IEGs c-fos and $\operatorname{arc}$, and to block dopamine (DA) uptake.

\section{Materials and Methods}

Experiment 1: psychomotor sensitization

Subjects. Male Sprague Dawley rats (Harlan Sprague Dawley, Indianapolis, IN), weighing 200-250 gm on arrival, were housed individually in a climate-controlled colony room maintained on a 14/10 hr light/dark cycle (lights on at 8:00 A.M.). All experiments were performed in compliance with the University of Michigan Committee on the Use and Care of Animals.

Surgical procedures. After 1 week of acclimation to the animal colony, animals were anesthetized with a mixture of ketamine and xylazine (77: $1.5 \mathrm{mg} / \mathrm{ml}$, i.p., at $0.1 \mathrm{ml} / 100 \mathrm{gm}$ of body weight) and instrumented with intravenous catheters using procedures described previously (Weeks, 1972; Crombag et al., 1996). After surgery, the animals' catheters were flushed with $0.02 \mathrm{ml}$ of a Gentamicin solution $(50 \mathrm{mg} / \mathrm{kg}$, dissolved in water) and $0.1 \mathrm{ml}$ of $0.9 \%$ sterile bacteriostatic saline. Starting $2 \mathrm{~d}$ after surgery, and for the duration of the experiment, the catheters were flushed manually with $0.1 \mathrm{ml}$ of $0.9 \%$ sterile bacteriostatic saline once per day. Three days after surgery, catheters were screened for patency by manually injecting $0.1 \mathrm{ml}$, i.v., of the short-acting barbiturate sodium 
thiopenthal $(20 \mathrm{mg} / \mathrm{ml}$ in sterile water). Rats that became ataxic within 5 sec were considered to have patent catheters and were transported to a testing room where they were housed for the duration of the experiment. Rats that did not become ataxic were excluded from the experiment. Catheter patency was verified again the day after the last test session, and only data from animals with patent catheters were used.

Apparatus. Circular plastic buckets $36 \mathrm{~cm}$ in height and $25 \mathrm{~cm}$ in diameter with granulated corncob bedding covering the base served as test cages. Each bucket was equipped with a photocell-based automated rotometer that recorded the total number of quarter $\left(90^{\circ}\right)$ turns in each direction using an XT-based personal computer (McFarlane et al., 1992). The number of quarter turns to the left and to the right were summed and used as an index of locomotor activity. During the testing sessions, each rat was tethered to a liquid swivel (Instech Laboratories, Plymouth Meeting, PA) via a flexible stainless steel cable. The swivel was fixed on a counter-balanced arm that allowed animals to move freely in the test environment. Each animal's catheter was connected to the swivel by a length of Tygon tubing that served as the drug/vehicle infusion line. A second length of tubing connected the swivel to a pump-driven syringe.

Groups and procedures. Two days after being transferred to the testing buckets, one-half of the animals received an intravenous infusion of saline $(10 \mu \mathrm{l})$ over $5 \mathrm{sec}$, and the other half received an intravenous infusion of saline over $100 \mathrm{sec}$. The next day, animals previously infused with saline over $5 \mathrm{sec}$ were now infused over $100 \mathrm{sec}$, and vice versa. These served as habituation days to acclimatize the animals to the testing procedures. One day later (day 1), the experimenter filled the infusion lines with $10 \mu \mathrm{l}$ of saline or $10 \mu \mathrm{l}$ of cocaine (dissolved in $0.9 \%$ saline) separated from the rest of the saline-filled infusion line by a small air bubble. The animals' catheters were then flushed manually with $0.1 \mathrm{ml}$ of $0.9 \%$ sterile bacteriostatic saline, connected to the infusion lines, and tethered to the swivels by flexible stainless steel cables. Independent groups of animals were administered $0.5 \mathrm{mg} / \mathrm{kg}(n=8-9 /$ infusion rate) or 2.0 $\mathrm{mg} / \mathrm{kg}(n=20-23 /$ infusion rate) cocaine in a fixed volume of saline (10 $\mu \mathrm{l})$ over $5 \mathrm{sec}(168.4 \mu \mathrm{l} / \mathrm{min}), 25 \mathrm{sec}(24.6 \mu \mathrm{l} / \mathrm{min})$, or $100 \mathrm{sec}(6.09$ $\mu \mathrm{l} / \mathrm{min})$, or saline over $5 \mathrm{sec}(n=10)$. The animals were left undisturbed for $40 \mathrm{~min}$, during which time baseline levels of locomotor activity were monitored. The experimenter then manually activated the pumps in the room so that the drug-saline solution was delivered simultaneously to all animals, regardless of infusion rate. A 30 min test period followed, during which locomotor activity was recorded. At the end of this session, animals were disconnected from their tethers. The next day (day 2), all drug-treated animals received an infusion of cocaine at the same dose/ rate they had received on day 1 . Animals that had received saline on day 1 received saline again on day 2 .

\section{Experiment 2: IEG expression}

Experiment 2 was designed to characterize the influence of infusion rate on the ability of cocaine to engage the mesocorticolimbic system using c-fos and $\operatorname{arc}$ mRNA as markers of cell activity. In addition, we examined the effects of infusion rate on cocaine-evoked c-fos expression in the two major subpopulations of projection neurons comprising the caudateputamen $(\mathrm{CPu})$.

Groups and procedures. After recovery from intravenous catheter implantation, animals with patent catheters were housed in the circular test cages described in experiment 1 . Two days later, animals were tethered and administered an intravenous infusion of saline either over 5 or 100 sec. The following day, animals that had previously received saline over 5 sec were now infused over $100 \mathrm{sec}$, and vice versa. One day later, animals received an infusion of 0.5 or $2.0 \mathrm{mg} / \mathrm{kg}$ cocaine over $5 \mathrm{sec}(n=12 / \mathrm{dose})$, $25 \sec (n=11 /$ dose $)$, or $100 \sec (n=12 /$ dose $)$, or saline over $5 \sec (n=$ 8 ), as described above. Thirty minutes later, animals were disconnected from their tethers, and catheter patency was assessed by manually injecting $0.1 \mathrm{ml}$, i.v., of sodium thiopenthal $(20 \mathrm{mg} / \mathrm{ml})$. Animals with patent catheters were transported immediately to a separate room and decapitated. Their brains were removed, frozen rapidly in isopentane $(-40$ to $-50^{\circ} \mathrm{C}$ ) on dry ice, and then stored at $-80^{\circ} \mathrm{C}$.

Single in situ hybridization. Coronal brains sections $(16 \mu \mathrm{m})$ were cut on a cryostat at $200 \mu \mathrm{m}$ intervals from $\sim+3.8$ to $-0.8 \mathrm{~mm}$ relative to bregma. Sections were thaw-mounted onto Superfrost/Plus slides (four sections per slide; Fisher Scientific, Pittsburgh, PA) and stored at $-80^{\circ} \mathrm{C}$ until processed. Adjacent brain sections were processed for single in situ hybridization of c-fos or arc mRNA using ${ }^{35}$ S-UTP- and -CTP-labeled riboprobes complementary to c-fos (680-mer, linearized from c-fos plasmid donated by Dr. T. Curran, St. Jude Children's Research Hospital, Memphis, TN) or arc mRNA (730-mer, linearized from arc plasmid donated by Dr. P. Worley, Johns Hopkins School of Medicine, Baltimore, MD) according to a protocol adapted from Cullinan et al. (1995) and described in detail by Uslaner et al. (2001).

Double in situ hybridization. There are two major subpopulations of projection neurons in the $\mathrm{CPu}$. One population forms the striatopallidal pathway and preferentially expresses mRNA for preproenkephalin (i.e., Enk + cells), whereas the other population forms the striatonigral pathway and does not express preproenkephalin mRNA (i.e., Enk - cells) (Gerfen, 1992). We used dual in situ hybridization histochemistry to examine the effect of delivery rate on cocaine-induced c-fos expression in both Enk + and Enk - cells in the CPu. Colocalization experiments have previously been conducted in our laboratory to examine the degree to which preproenkephalin mRNA is colocalized with either preprodynorphin or preprotachykinin mRNAs in the $\mathrm{CPu}$. These control studies demonstrated that the majority ( $96.3 \%$ of 2154 cells) of cells containing the preproenkephalin probe were not colabeled with either the preprodynorphin or preprotachykinin probes (Uslaner et al., 2003b).

Sections containing the $\mathrm{CPu}$ were processed for dual in situ hybridization of a ${ }^{35} \mathrm{~S}-\mathrm{UTP}$ - and -CTP-labeled riboprobe complementary to c-fos mRNA and a digoxigenin-UTP-labeled riboprobe complementary to preproenkephalin mRNA (693-mer, linearized from preproenkephalin plasmid courtesy of Dr. J. Douglass, Amgen, Thousand Oaks, CA) using a method adapted from Curran and Watson (1995) and described in detail by Ferguson et al. (2004). The radioactive riboprobe was generated as described above.

Quantification of single in situ. Sections were exposed to x-ray film (Kodak Biomax-MR; Eastman Kodak, Rochester, NY) for 3-4 d. Autoradiographs of brain sections were captured digitally and used to analyze mRNA levels. The magnitude of the signal from the radioactive probes in single-labeled sections was determined using NIH Image (version 1.61 for Macintosh computer), which automatically determined signal above background in each brain region (macro written by Dr. S. Campeau, University of Colorado, Boulder, CO). A background value was obtained from the corpus callosum in each section, and only pixels with a mean gray value exceeding the background value by $3.5 \mathrm{SD}$ were included in the analysis. Results are expressed as the mean integrated density of signal pixels divided by the total number of pixels in the selected region.

Anatomical regions were identified and subdivided for densitometric analysis according to the stereotaxic atlas of Paxinos and Watson (1997). c-fos and arc mRNA levels were quantified in the medial prefrontal cortex (mPFC), which was divided into Cg1/prelimbic (Cg1/Prl) and infralimbic (IL) areas; the orbital cortex, which was divided into ventral and lateral regions; the nucleus accumbens (Nacc), which was divided into core and shell; and the $\mathrm{CPu}$, which was divided into dorsomedial (DM), dorsolateral (DL), ventromedial, and ventrolateral (VL) sectors. In addition, c-fos mRNA levels in the CPu were analyzed in six distinct sampling areas defined by their predominant cortical inputs, as described by Willuhn et al. (2003). These consisted of a medial (M), dorsal (D), DL, VL, ventral $(\mathrm{V})$, and central $(\mathrm{C})$ sector. Integrated density values in these six sampling sectors ranged from 0.01 to 0.03 in saline-treated animals, therefore these values were subtracted from those of individual animals in each cocaine-treated group, as shown in Figure $5 e$ (brain diagram modified from a digital illustration provided by Dr. H. Steiner, Finch University of Health Sciences, The Chicago Medical School, Chicago, IL).

Quantification of double in situ. Integrated density measurements of c-fos mRNA expression across the rostrocaudal axis of the $\mathrm{CPu}$ indicated that the effect of infusion rate was greatest in the DM quadrant of sections $0.0 \mathrm{~mm}$ relative to bregma. This region was therefore selected for analysis of double-labeled cells. Total numbers of single- and double-labeled cells were counted in a $500 \times 1000 \mu \mathrm{m}$ area in each hemisphere using a microscope (Leitz DMR; Leica, Wetzler, Germany) at $400 \times$ total magnification. Data from the two hemispheres of each animal were subsequently combined for statistical analysis. Digoxigenin-labeled cells (con- 


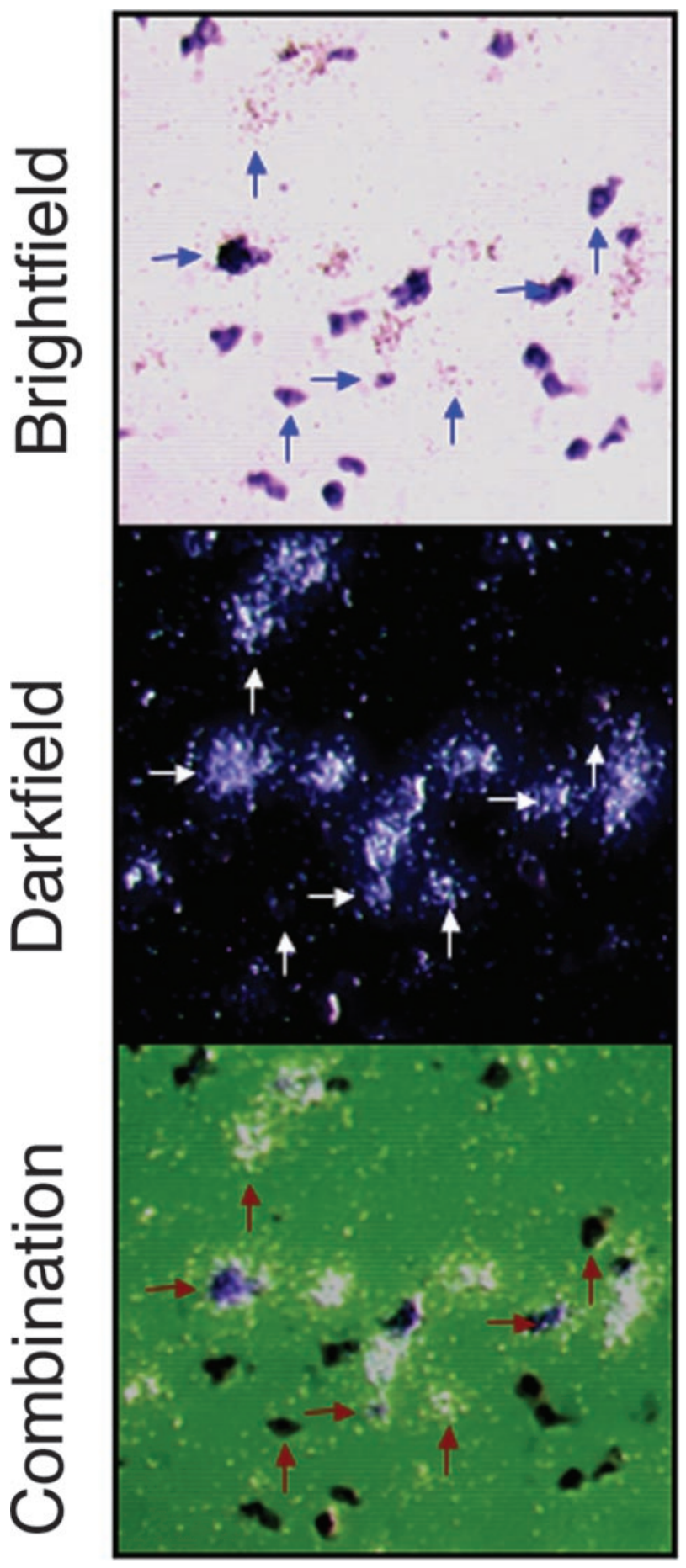

Figure 1. Representative histological plates from the DM CPu showing cells double labeled for c-fos mRNA and preproenkephalin mRNA. Top, Bright-field images in which Enk + cells appear as purple precipitate. Middle, Dark-field images in which c-fos + cells appear as silver grain clusters. Bottom, 0 verlay of bright-field and dark-field images. The vertical arrows indicate single-labeled cells ( $c$-fos or Enk + mRNA), and horizontal arrows indicate double-labeled cells (c-fos/Enk + ).

taining preproenkephalin mRNA) appeared as a purple precipitate under bright-field conditions, and ${ }^{35}$ S-labeled cells (containing c-fos mRNA) were seen as densely packed silver grain clusters under dark-field conditions (Fig. 1).

\section{Experiment 3: DA uptake inhibition}

The purpose of experiment 3 was to investigate the effect of cocaine infusion rate on reuptake blockade of electrically evoked DA overflow in the Nacc core. Accumbal DA release was induced by brief electrical stimulations of the medial forebrain bundle (MFB) and monitored using continuous amperometry with untreated carbon fiber electrodes (Dugast et al., 1994; Michael and Wightman, 1999).

MFB electrical stimulation. Experiments were performed in accordance with French (87-848, Ministère de l'Agriculture et de la Forêt) and European Economic Community (86-6091) guidelines for care of laboratory animals. Male Sprague Dawley rats (330-370 gm; Charles River, Lyon, France) were anesthetized with urethane (1.15-1.3 gm/kg, i.p.) and fitted with jugular catheters. Animals were then fixed in a stereotaxic frame and maintained at $37^{\circ} \mathrm{C}$. In each animal, a bipolar stimulating electrode (SNEX-200; Rhodes Medical Instruments, Summerland, CA) was lowered into the MFB $3.5 \mathrm{~mm}$ posterior to bregma and $1.2 \mathrm{~mm}$ lateral to midline. The depth of the stimulating electrode was adjusted for each animal so that electrical stimulation evoked a maximal DA response. Stimulation pulses $(0.5 \mathrm{msec}, 300 \mu \mathrm{A})$ were applied using an isolated stimulator (DS3 Digitimer; DS3, Hertfordshire, UK) triggered by a MacLab system (AD Instrument, Castle Hill, Australia).

Amperometry. The electrochemical technique used here, continuous amperometry with untreated carbon fiber electrodes, provides excellent time resolution and sensitivity. Unfortunately, this technique exhibits a poor chemical resolution compared with other voltammetric techniques and can only be used in anesthetized rodents to monitor the DA overflow evoked by brief MFB electrical stimulations (Dugast et al., 1994; Michael and Wightman, 1999). However, with respect to brief DA overflow in rodents, the validity of this approach has been confirmed by anatomical, pharmacological, and physiological data (Dugast et al., 1994; SuaudChagny et al., 1995; Benoit-Marand et al., 2000). Moreover, results obtained with this technique are in excellent agreement with similar observations provided by fast-scan cyclic voltammetry (Garris et al., 1994; Michael and Wightman, 1999; Venton et al., 2003).

The electrodes were "unsized" carbon fibers with an active surface 7 $\mu \mathrm{m}$ in diameter and $250 \mu \mathrm{m}$ long (product number C005722; Goodfellow Corporation, Berwyn, PA). The dura mater was punctured by a used carbon fiber electrode, and a new electrode was lowered through this hole into the core of the Nacc (1.4 mm lateral to the midline, $1.5-2.0 \mathrm{~mm}$ anterior to bregma, and $6.75 \mathrm{~mm}$ below the cortical surface). The reference electrode was a silver wire coated with $\mathrm{AgCl}$ and was maintained in contact with the skull by a sponge moistened with a $0.9 \% \mathrm{NaCl}$ solution. A two-electrode potentiostat (AMU 130; Radiometer Analytical, Villeurbanne, France) was used to apply $+0.4 \mathrm{~V}$ to the carbon fiber electrode relative to the reference electrode and to record the current passing through them. The amplified signal was digitized at $1 \mathrm{kHz}$ by a MacLab system coupled with a Macintosh computer running the Scope program (AD Instruments). Train-pulse stimulations consisting of four pulses at $100 \mathrm{~Hz}$ were applied every $10 \mathrm{sec}$ for $50 \mathrm{~min}$. The time interval between train-pulse stimulations was chosen after preliminary experiments so that consecutive individual evoked responses were stable in terms of kinetics and amplitude.

Each animal's catheter was connected to a pump-driven syringe by a length of Tygon tubing that served as the drug/vehicle infusion line. The pumps were set to infuse vehicle or $2.0 \mathrm{mg} / \mathrm{kg}$ cocaine over 5,25 , or 100 $\mathrm{sec}$ in a volume of $10 \mu \mathrm{l}$. Five animals were used in each condition. Baseline measurements were taken for 5 min before the pump was manually activated, and measurements of DA reuptake inhibition continued for $45 \mathrm{~min}$ after the infusion.

Before and after each recording period (at $+0.4 \mathrm{~V}$ ), the amperometric current was also recorded while the carbon fiber electrode was held at 0.0 $\mathrm{V}$. At $0.0 \mathrm{~V}, \mathrm{DA}$ is not oxidized, and only transient electrical artifacts attributable to the stimulation are recorded (Dugast et al., 1994). To improve the recording of oxidation currents, these artifacts were removed by subtracting data obtained at $0.0 \mathrm{~V}$ from those recorded at +0.4 V. In some experiments, the variations in the oxidation current were estimated in terms of changes in extracellular DA concentration on the basis of in vitro calibration of the carbon fiber electrode performed after in vivo measurements, as described previously (Dugast et al., 1994). After each experiment, the anatomical location of the recording electrode was verified by electrolytic lesion of the tissue surrounding the carbon fiber. The brain was removed, frozen at $-80^{\circ} \mathrm{C}$, and cryostat sectioned into 
$30-\mu \mathrm{m}$-thick sections that were then stained with toluidine blue. Experiments in which the recording site was not in the core of the Nacc were not used.

Quantification of DA reuptake-inhibition. Dopamine half-life was used as an index of uptake efficiency (Suaud-Chagny et al., 1995; BenoitMarand et al., 2000). It was measured from evoked DA overflow using the Scope software and corresponded to the time to $50 \%$ decay from the point in which the maximal overflow was reached (see Fig. $6 a$ ). To accurately measure this parameter every $20 \mathrm{sec}$, single recordings made every $20 \mathrm{sec}$ were averaged with the preceding and following one. Peak levels of DA uptake inhibition in each condition were calculated by averaging the three data points immediately after the rising phase of each curve. Because the rate of cocaine administration was varied, the duration of the rising phase of reuptake inhibition varied as well, lasting longer after slower infusions. Consequently, values representing peak DA uptake inhibition were selected at later time points with slower infusion rates.

\section{Statistical analyses}

Experiment 1. On day 1, the influence of infusion rate on the acute locomotor response to $2.0 \mathrm{mg} / \mathrm{kg}$ cocaine was assessed using a one-way ANOVA, followed by Tukey's multiple comparison test. The influence of infusion rate on the development of locomotor sensitization was assessed using planned paired $t$ tests comparing locomotor counts on days 1 and 2 for each group. Sensitization is indicated by a significant increase in locomotor activity from day 1 to day 2 .

Experiment 2. In brain regions in which IEG expression was assessed at one rostrocaudal level (e.g., the mPFC, the orbitofrontal cortex, as well as in the analysis of c-fos mRNA density in the six sampling sectors of the $\mathrm{CPu}$, and in Enk - vs Enk + striatal cells), group differences were assessed using a one-way ANOVA, followed by Tukey's multiple comparison test (comparing all groups to each other). In brain regions in which IEG expression was assessed at several rostrocaudal levels (e.g., the $\mathrm{CPu}$ and the Nacc), group differences were first assessed using an overall two-way ANOVA (condition $\times$ rostrocaudal position). If either the main effect or interaction term was significant, two-way ANOVAs comparing the experimental groups to control and to each other were performed.

Experiment 3. Group differences in DA uptake inhibition over time were assessed using two-way ANOVAs (condition $\times$ time) comparing all experimental groups to control and to each other. Group differences in peak DA uptake inhibition were assessed using a one-way ANOVA, followed by Tukey's multiple comparison test.

\section{Results}

\section{Experiment 1: psychomotor sensitization}

There was no difference in the locomotor response to $0.5 \mathrm{mg} / \mathrm{kg}$ cocaine between days 1 and 2, at any infusion rate tested, indicating that none of the animals developed behavioral sensitization at this dose (data not shown). On day 1,2.0 mg/kg cocaine increased locomotor activity in all groups (one-way ANOVA, followed by Tukey's multiple comparison test; $F_{(3)}=5.16 ; p<0.05$; post hoc, $P<0.05$ ), but there was no effect of infusion rate (Fig. 2). On day 2 , only animals infused with cocaine over $5 \mathrm{sec}$ showed a significant increase in locomotor activity relative to day 1 (paired $t$ test; $t=-3.306 ; p<0.004$ ), indicating that a single infusion of cocaine produced sensitization only when it was delivered rapidly $(5 \mathrm{sec})$.

\section{Experiment 2: IEG expression}

At all infusion rates tested, $0.5 \mathrm{mg} / \mathrm{kg}$ cocaine induced very low levels of both c-fos and arc mRNA expression relative to vehicle controls (data not shown). In addition, the IEG response to this dose of cocaine did not vary as a function of infusion rate. Therefore, data from animals treated with $0.5 \mathrm{mg} / \mathrm{kg}$ cocaine were not included in the analyses, and all subsequent data are from animals given $2.0 \mathrm{mg} / \mathrm{kg}$.

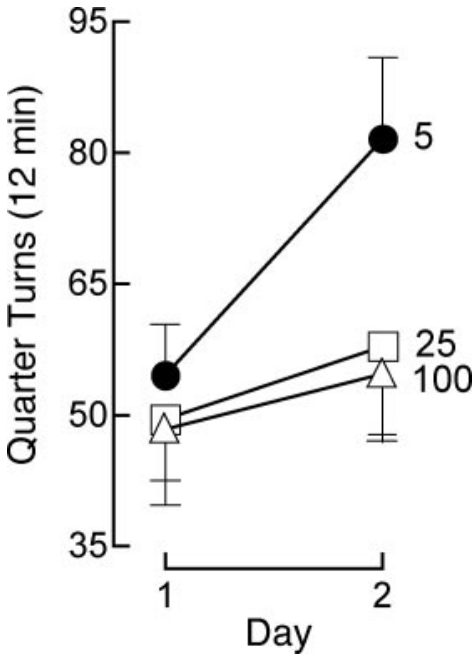

Figure 2. Locomotor activity (quadrant entries) averaged over the first $12 \mathrm{~min}$ after an intravenous infusion of $2.0 \mathrm{mg} / \mathrm{kg}$ cocaine given over 5,25 , or $100 \mathrm{sec}$, on 2 consecutive days (values are mean $\pm \mathrm{SEM}$ ).
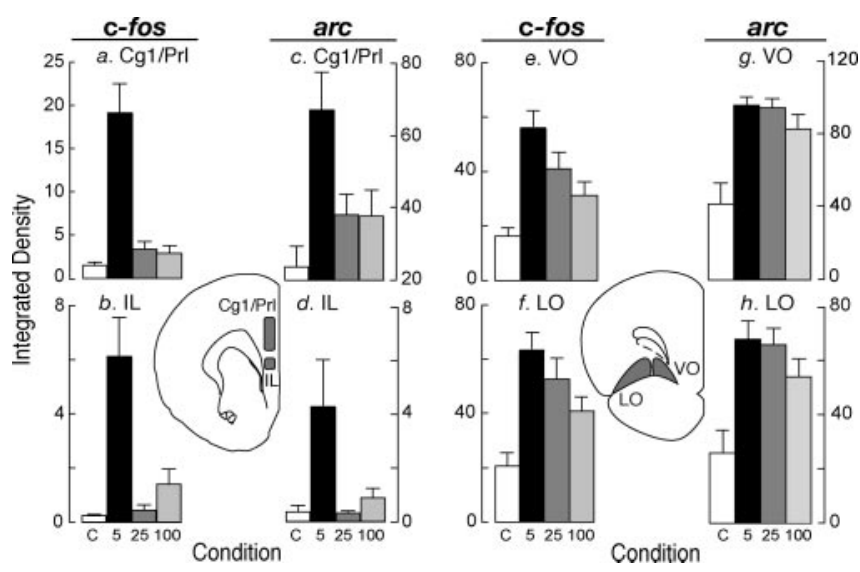

Figure 3. The effect of infusion rate on cocaine-induced c-fos and $\operatorname{arc}$ RRNA in the medial prefrontal and orbitofrontal cortices (values are mean \pm SEM).

Medial prefrontal and orbitofrontal cortices

In the Cg1/Prl and IL subdivisions of the mPFC (Fig. $3 a-d$ ), cocaine increased c-fos and arc expression above control levels only when it was administered over $5 \mathrm{sec}$ (one-way ANOVAs, followed by Tukey's multiple comparison tests; $a, F_{(3)}=19 ; b$, $F_{(3)}=12 ; c, F_{(3)}=4.8 ; d, F_{(3)}=5.9 ; P<0.01 ; 5$ sec vs saline, $P<$ $0.01)$, and there was a significant effect of rate of infusion $(5>$ $25-100$ in all cases; $a-d, P s<0.05$; the 5 and 25 sec groups did not statistically differ in $d$ ). In the ventral (VO) and lateral (LO) subdivisions of the orbitofrontal cortex (Fig. 3e,f), cocaine increased c-fos expression above control when it was infused over $5-25 \sec \left(e, F_{(3)}=8.1 ; f, F_{(3)}=7.5 ; P<0.005\right.$; post hoc, $\left.P<0.05\right)$ but not $100 \mathrm{sec}$, and there was a significant effect of rate of infusion $(5>100 \mathrm{sec} ; P<0.05)$. In contrast, cocaine induced arc mRNA expression in the $\mathrm{LO}$ and $\mathrm{VO}$ above control at all infusion rates (Fig. $3 g, h)\left(g, F_{(3)}=10 ; h, F_{(3)}=6.1 ; P<0.002\right.$; post hoc, $P<0.01$; with the exception of the $100 \mathrm{sec}$ group in the LO), and there was no effect of infusion rate.

Nacc core and shell

In both the Nacc core and shell (Fig. $4 a-d$ ), all drug treatments increased c-fos and arc expression above control levels (two-way ANOVAs, main effects of condition; $a$ : $5 \mathrm{sec}>$ sal, $F_{(1,18)}=25.53$; 

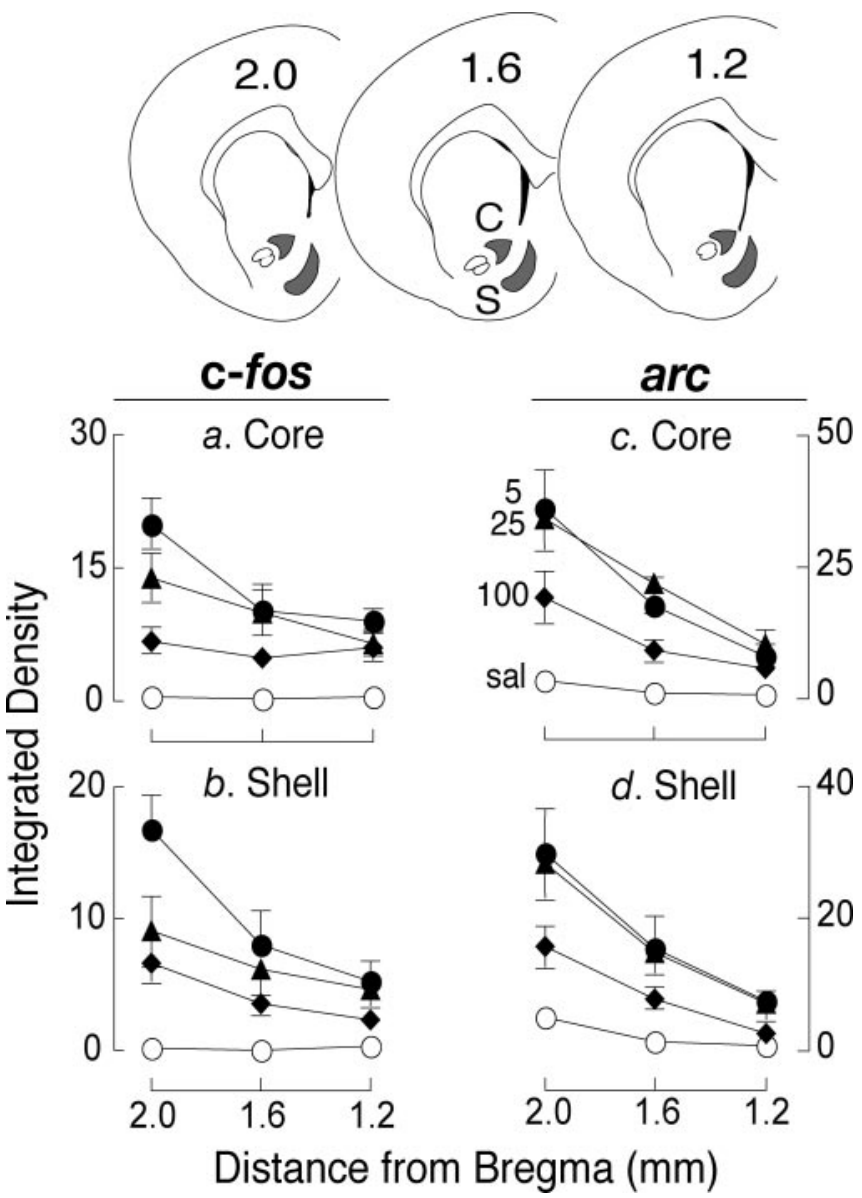

Figure 4. c-fos and arc mRNA expression at three levels of the Nacc core and shell as a function of cocaine infusion rate (values are mean \pm SEM)., Animals in the 5 sec group; $\boldsymbol{\Delta}$, animals in the 25 sec group; $\diamond$, animals in the 100 sec group; $\bigcirc$, control animals.

$25 \mathrm{sec}>\mathrm{sal}, F_{(1,17)}=17.21 ; 100 \mathrm{sec}>\mathrm{sal}, F_{(1,18)}=10.43 ; b: 5$ $\sec >$ sal, $F_{(1,18)}=14.95 ; 25 \mathrm{sec}>$ sal, $F_{(1,17)}=24.9 ; 100 \mathrm{sec}>\mathrm{sal}$, $F_{(1,18)}=10.83 ; c: 5 \mathrm{sec}>$ sal, $F_{(1,18)}=11.17 ; 25 \mathrm{sec}>$ sal, $F_{(1,17)}=$ $15.22 ; 100 \mathrm{sec}>$ sal, $F_{(1,18)}=8.07 ; d, 5 \mathrm{sec}>\operatorname{sal}, F_{(1,18)}=7 ; 25$ sec $>$ sal, $F_{(1,17)}=13.82 ; 100 \mathrm{sec}>$ sal, $\left.F_{(1,18)}=8.86 ; P<0.05\right)$, and this effect was greatest in the rostral Nacc (i.e., level 2.0 relative to bregma). In addition, cocaine induced greater c-fos and arc expression in the core and shell when it was given over $5 \mathrm{sec}$ than over $100 \mathrm{sec}$ (Fig. $4 a-d$ ) (condition $\times$ rostrocaudal position; $a$, $F_{(2,44)}=7.15 ; b, F_{(2,44)}=7.18 ; c, F_{(2,44)}=3.6 ; P<0.04$; these groups were not significantly different in $d$ ), and when it was given over $25 \mathrm{sec}$ than over $100 \mathrm{sec}(a$, condition $\times$ rostrocaudal position: $F_{(2,42)}=4.61, p<0.02 ; c, d$, main effects of condition: $F_{(1,21)}=4.53, F_{(1,21)}=5.02$, respectively; $P<0.05$; these groups were not significantly different in $b$ ).

\section{Caudate-putamen}

Figure 5 shows representative densitograms illustrating c-fos mRNA expression in the brains of animals given cocaine over 5 , 25 , or $100 \mathrm{sec}$, or vehicle over $5 \mathrm{sec}$, and illustrates the analysis of c-fos mRNA density in the $\mathrm{CPu}$ as a function of rate of cocaine administration. The effect of infusion rate on cocaine-induced arc expression in the $\mathrm{CPu}$ was essentially the same as with c-fos, and therefore the data are not presented. In all quadrants of the $\mathrm{CPu}($ Fig. $5 a-d)$, all drug treatments induced greater c-fos expression than saline (two-way ANOVAs, main effects of condition; $a$ : $5 \mathrm{sec}>\mathrm{sal}, F_{(1,16)}=24.05 ; 25 \mathrm{sec}>\mathrm{sal}, F_{(1,16)}=10.57 ; 100 \mathrm{sec}>$ sal, $F_{(1,17)}=4.22 ; b: 5 \mathrm{sec}>\mathrm{sal}, F_{(1,17)}=33.15 ; 25 \mathrm{sec}>\operatorname{sal}, F_{(1,16)}$ $=11.74 ; 100 \mathrm{sec}>$ sal, $F_{(1,17)}=5.69 ; c: 5 \mathrm{sec}>$ sal, $F_{(1,17)}=18.5$; $25 \mathrm{sec}>$ sal, $F_{(1,16)}=8.98 ; 100 \mathrm{sec}>$ sal, $F_{(1,17)}=6.42 ; d: 5 \mathrm{sec}>$ sal, $F_{(1,17)}=25.38 ; 25 \mathrm{sec}>$ sal, $F_{(1,16)}=13.5 ; 100 \mathrm{sec}>$ sal, $F_{(1,17)}$ $=6.89 ; P<0.05)$, and there was a large effect of rate of infusion (condition $\times$ rostrocaudal position: $a: 5>25 \mathrm{sec}, F_{(4,80)}=3.07$; $5>100 \mathrm{sec}, F_{(4,84)}=8.45 ; 25>100 \mathrm{sec}, F_{(4,84)}=3.87 ; P<0.02$; $b: 5>25 \mathrm{sec}, F_{(4,84)}=4.66 ; 5>100 \mathrm{sec}, F_{(4,88)}=8.88 ; P<0.002$; main effects of condition: $c: 5>25 \mathrm{sec}, F_{(1,21)}=4.94 ; 5>100 \mathrm{sec}$, $\left.F_{(1,22)}=15.06 ; P<0.04 ; d, 5>100 \mathrm{sec}, F_{(1,22)}=9 ; p<0.007\right)$.

The effect of infusion rate on $c$-fos induction was greatest at level 0.0 relative to bregma, therefore we analyzed the distribution of c-fos expression at this level in more detail by dividing the $\mathrm{CPu}$ into six sectors based on their predominant cortical projections as described by Willuhn et al. (2003). Rapid infusions of cocaine induced the most c-fos mRNA in all striatal sectors (Fig. $5 e$ ) (one-way ANOVAs, followed by Tukey's multiple comparison tests; sector M: $5>25-100 \mathrm{sec}, P<0.05$; in all but the ventral $\mathrm{V}$ and VL sectors: $5>100 \mathrm{sec}, P<0.05)$. We also analyzed the effects of infusion rate on cocaine-induced c-fos mRNA in Enkversus Enk+ cells within the DM CPu (Fig. 5f,g). Cocaine increased c-fos expression in Enk - cells only when it was infused over 5-25 sec (Fig. 5f) $\left(F_{(3)}=14 ; p<0.0001\right.$; post hoc, $\left.P<0.01\right)$, and the number of $\mathrm{c}-\mathrm{fos} / \mathrm{Enk}-$ cells was greater after infusions over $5 \mathrm{sec}$ than over $25-100 \mathrm{sec}$ (Fig. $5 f)(P<0.05)$. In addition, infusions over $5 \mathrm{sec}$ led to a greater increase in c-fos expression in Enk + neurons relative to all other conditions (Fig. $5 g)\left(F_{(3)}=13\right.$; $P<0.01)$.

\section{Experiment 3: DA reuptake inhibition}

Cocaine increased DA half-life above control in all drug-treated groups (Fig. 6b) (two-way ANOVAs, condition $\times$ time interactions: $5 \mathrm{sec}>$ sal, $F_{(15,120)}=17.38 ; 25 \mathrm{sec}>$ sal, $F_{(15,120)}=22.95$; $\left.100 \mathrm{sec}>\operatorname{sal}, F_{(15,120)}=26.37 ; P<0.0001\right)$, although the kinetics and amplitude of DA reuptake inhibition by cocaine varied with rate of infusion. Time to reach peak DA uptake inhibition was shorter with faster infusions (Fig. 6b) (condition $\times$ time interaction in the first $5 \mathrm{~min}$ after cocaine; $5>25 \mathrm{sec}, F_{(15,120)}=2.40$; $5>100 \mathrm{sec}, F_{(15,120)}=10.67 ; 25>100 \mathrm{sec}, F_{(15,120)}=4.99 ; P<$ 0.005). Maximal levels of DA reuptake inhibition occurred within $60 \mathrm{sec}$ after a $5 \mathrm{sec}$ cocaine infusion, within $100 \mathrm{sec}$ after a $25 \mathrm{sec}$ infusion, and within $180 \mathrm{sec}$ after a $100 \mathrm{sec}$ infusion. In addition, the peak amount of reuptake inhibition by cocaine was greater when it was infused over $5 \mathrm{sec}$ than over $100 \mathrm{sec}$ (Fig. $6 c)(p<0.05)$.

\section{Discussion}

It is commonly believed that addiction liability increases as the speed with which drugs of abuse reach the brain increases (Gossop et al., 1992, 1994; Winger et al., 1992; Hatsukami and Fischman, 1996). This is why, for example, smoked cocaine ("crack") is thought to be more addictive than powdered cocaine taken by insufflation (Hatsukami and Fischman, 1996). Two related mechanisms have been proposed to account for this relationship. First, rapidly administered drugs produce more immediate and more intense subjective pleasurable effects (de Wit et al., 1993; Hatsukami and Fischman, 1996). Indeed, subjective reports of drug liking are greatest when psychoactive drugs such as diazepam (de Wit et al., 1993), methylphenidate (Kollins et al., 1998), and cocaine (Fischman and Schuster, 1984; Abreu et al., 2001) are administered rapidly. Second, the rapid administration of cocaine is reported to enhance its reinforcing efficacy. This idea comes from a small number of animal studies suggesting that 

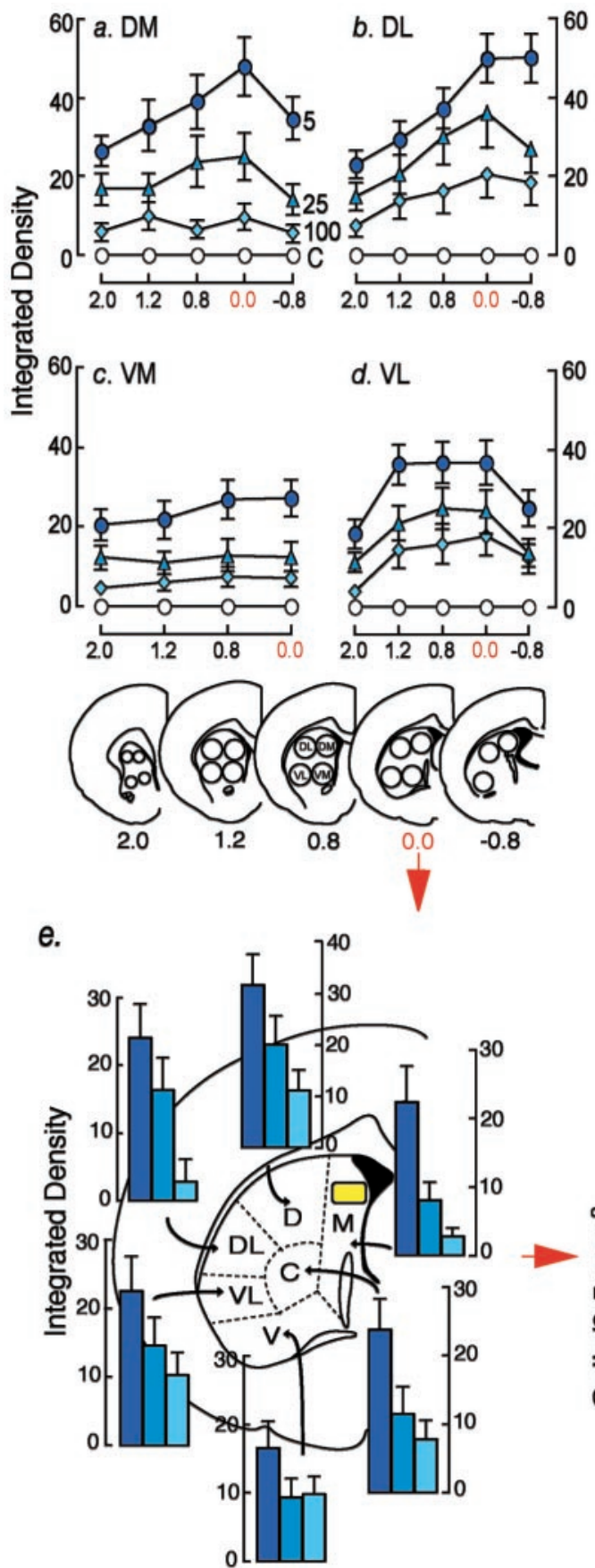
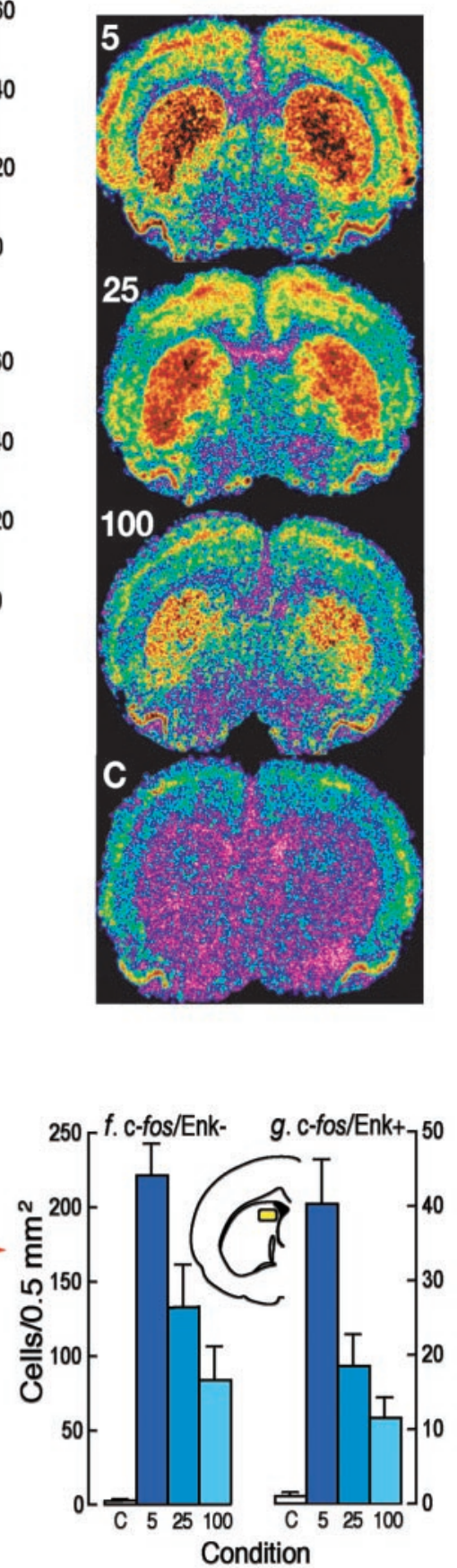

Figure 5. c-fos mRNA density in the (Pu as a function of rate of cocaine administration (values are mean $\pm S E M)$. Also included are representative densitograms illustrating c-fos mRNA levels in the brains of animals given cocaine over 5, 25, or $100 \mathrm{sec}$, or vehicle over $5 \mathrm{sec}$. In $a-d$, animals in the 5 sec group are represented by filled circles, animals in the 25 sec group are represented by filled triangles, animals in the 100 sec group are represented by filled diamonds, and control animals are represented by open circles.

rapid intravenous infusions of cocaine may be more effective in supporting self-administration behavior (Balster and Schuster, 1973; Kato et al., 1987; Panlilio et al., 1998). However, there is no compelling evidence for a necessary causal relationship between the euphorigenic properties of drugs and their ability to produce addiction (Robinson and Berridge, 1993). Furthermore, evidence that drug self-administration is influenced by small variations in the rate of administration is very limited. Indeed, consistent with previous findings using rats (Pickens et al., 1969), we recently reported that varying the infusion rate between 5 and $100 \mathrm{sec}$ has no effect on the acquisition of cocaine or amphetamine self-administration, reinstatement of extinguished drug seeking, or breakpoint achieved on a progressive ratio schedule of reinforcement (Crombag et al., 2003). Therefore, it is possible that increasing the rate of drug delivery increases the propensity to addiction by influencing other actions of drugs.

It has been suggested that the ability of drugs to induce forms of synaptic plasticity leading to behavioral sensitization may be important in the transition to addiction (Robinson and Berridge, 1993, 2003). Therefore, we predicted that the rate of cocaine administration may modulate its ability to produce behavioral sensitization. We found that although the acute locomotor response to an intravenous injection of cocaine did not vary as a function of infusion rate, behavioral sensitization developed to a single injection of $2.0 \mathrm{mg} / \mathrm{kg}$ cocaine when it was delivered over $5 \mathrm{sec}$ but not when it was given over 25 or $100 \mathrm{sec}$. These results are consistent with previous findings demonstrating that repeated infusions of rapidly delivered cocaine are particularly effective in inducing psychomotor sensitization (Samaha et al., 2002). It appears, therefore, that something about the temporal dynamics of rapid cocaine delivery to the brain renders animals especially susceptible to sensitization.

To investigate possible mechanisms, we used c-fos and arc mRNA to explore the brain regions engaged by cocaine as a function of delivery rate. The ability of drugs to induce IEGs is thought to represent a first step in a chain of molecular events leading to synaptic reorganization and forms of drug experience-dependent behavioral plasticity, such as sensitization (Hyman and Malenka, 2001; Nestler, 2001). We found that very small differences in the rate at which cocaine was administered resulted in strikingly different patterns of gene expression. IEG expression in the orbitofrontal cortex, the MPFC, the Nacc, and the $\mathrm{CPu}$ was markedly enhanced by the rapid delivery of cocaine. The dose of cocaine used here induced $\mathrm{c}$-fos and arc mRNA in the mPFC only when administered over $5 \mathrm{sec}$. The observation that rapidly administered cocaine preferentially engages components of the mesocorticolimbic system is consistent with a previous study by Porrino (1993) showing that cocaine increases metabolic activity in mesocorticolimbic structures when it is given intravenously, but not when given by the intraperitoneal route.

It is also interesting that the slower rates of cocaine infusion did not significantly increase the number of Enk + cells in the striatum that expressed c-fos mRNA, which is consistent with previous studies using intraperitoneal injections of the drug (Ber- 
a.
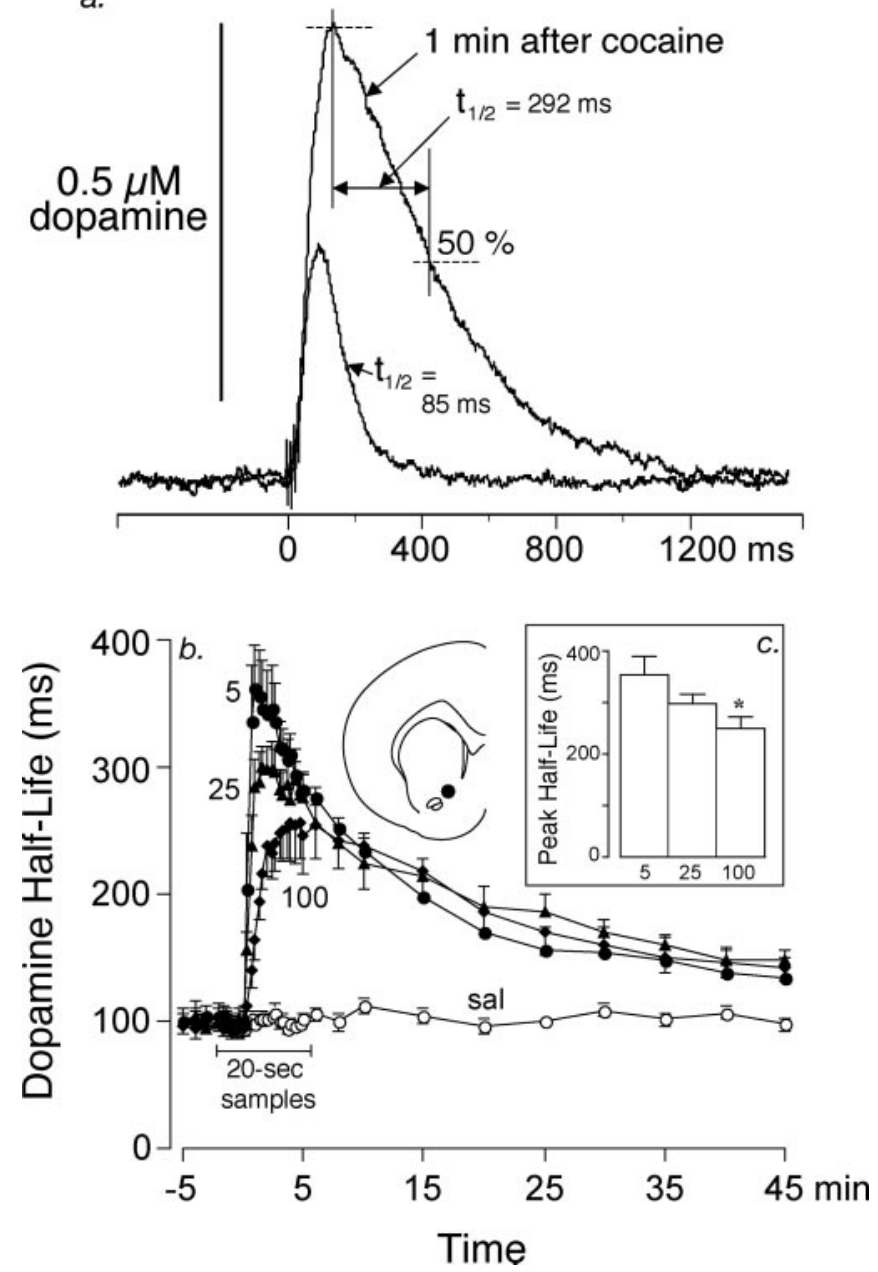

Figure 6. The effect of the infusion rate on the ability of cocaine to prolong the half-life (an index of reuptake inhibition) of electrically evoked DA release in the Nacc core. For illustrative purposes, a shows typical traces corresponding to the average of three consecutive individual recordings obtained just before an infusion of saline or cocaine $(2.0 \mathrm{mg} / \mathrm{kg}$ over $5 \mathrm{sec})$, and 50 , 60 , and 70 sec after injection, and shows how DA half-life $\left(t_{1 / 2}\right)$ was determined. $b$ shows the effect of the cocaine infusion rate on DA half-life (values are mean $\pm \mathrm{SEM}$ ). Animals in the $5 \mathrm{sec}$ group are represented by filled circles, animals in the $25 \mathrm{sec}$ group are represented by filled triangles, animals in the $100 \mathrm{sec}$ group are represented by filled diamonds, and control animals are represented by open circles. During the 2 min before and $3 \mathrm{~min}$ after the infusion, DA half-life is shown every $20 \mathrm{sec}$, and thereafter one sample is shown every $2 \mathrm{~min}$ for three consecutive data points and every 5 min for all subsequent data points. c shows peak levels of DA uptake inhibition by cocaine as a function of infusion rate (values are mean $\pm S E M$ ).

retta et al., 1992; Cenci et al., 1992). However, when administered over $5 \mathrm{sec}$, cocaine did induce c-fos in Enk + cells (as well as in Enk - cells). These findings are reminiscent of previous studies showing that when cocaine is administered under conditions that promote behavioral sensitization (i.e., in a novel environment), this also facilitates its ability to engage Enk + cells in the striatum (Uslaner et al., 2003a).

The ability of cocaine to evoke IEG expression (Young et al., 1991; Fosnaugh et al., 1995) and psychomotor activation (Wise and Bozarth, 1987) is dependent in part on its ability to increase DA neurotransmission by inhibiting the reuptake of DA. Therefore, we used in vivo voltammetry to examine DA uptake in the Nacc core as a function of rate of intravenous cocaine delivery. We found that intravenous cocaine produced a large increase in the half-life of electrically evoked DA, at all infusion rates tested, although the increase in DA half-life occurred faster and was of greater amplitude when cocaine was delivered rapidly. The maximal inhibition of DA uptake induced by $2.0 \mathrm{mg} / \mathrm{kg}$ cocaine given intravenously was comparable with that seen after an intraperitoneal injection of $20 \mathrm{mg} / \mathrm{kg}$ cocaine (Suaud-Chagny et al., 1995), but the kinetics were much faster with intravenous administration. Indeed, the increase in DA half-life peaked within 60-100 sec after an injection over 5-25 sec. These kinetics are also much faster than those reported recently by Kiyatkin et al. (2000), who found that peak inhibition did not occur until 6 min after a 12-15 sec intravenous injection of cocaine. It is not clear what accounts for this discrepancy, but there are two major methodological differences between these studies. First, Kiyatkin et al. (2000) used freely moving animals, whereas we studied the inhibition of DA uptake in urethane-anesthetized animals. However, it is unlikely that anesthesia would speed up the effects of cocaine. Indeed, Garris et al. (2003) investigated the effect of intraperitoneal administration of nomifensine on the DA overflow evoked by electrical stimulation in both urethane-anesthetized and freely moving rats and reported that the enhancing effect of nomifensine was actually somewhat slower in anesthetized animals. Second, Kiyatkin et al. (2000) monitored the rate of elimination of exogenously applied DA, whereas we monitored the half-life of endogenous DA released by brief electrical stimulation of the MFB. The half-life of exogenously applied DA is $\sim 10 \mathrm{sec}$ (from peak) according to Kiyatkin et al. (2000, their Fig. 1), whereas the half-life of endogenously released DA observed here, and by others (Garris et al., 1994; Suaud-Chagny et al., 1995; Venton et al., 2003), is in the range of 50-300 msec. Furthermore, the kinetics reported here are consistent with the rapid onset of behavioral effects reported by Kiyatkin et al. (2000) and by us (Samaha et al., 2002). Therefore, the approach used here may provide a more physiological estimate of the kinetics of DA uptake.

The ability of cocaine to enhance DA neurotransmission by inhibiting DA reuptake is thought to underlie its effects on IEG expression (Young et al., 1991; Fosnaugh et al., 1995). If the effect of cocaine infusion rate on IEG expression described here is mediated primarily through its effects on DA, then it follows that very small and very brief differences in extracellular DA levels (at least as estimated by the change in DA half-life) must lead to relatively large differences in IEG expression. For example, although cocaine induced considerably greater IEG expression in the Nacc core when it was injected over $25 \mathrm{sec}$ than over $100 \mathrm{sec}$, differences in DA reuptake inhibition between these conditions only lasted for $\sim 3 \mathrm{~min}$ (Fig. 6b). For the remaining 30-40 min before the drug response returned to baseline, there was absolutely no effect of rate of infusion on DA half-life (or presumably extracellular DA levels). Furthermore, variation in IEG expression was not always predicted by variation in DA uptake inhibition. For example, there was no significant difference in peak DA reuptake inhibition in the Nacc core after a cocaine infusion over $25 \mathrm{sec}$ versus $100 \mathrm{sec}$, but the former evoked significantly greater levels of both c-fos and arc expression. Therefore, it is possible that non-dopaminergic mechanisms contribute to the effect of infusion rate on cocaine-induced IEG expression.

Previous authors have highlighted the importance of glutamatergic systems in orchestrating the IEG response to cocaine (Torres and Rivier, 1993). Our data provide a number of reasons to speculate that the effect of infusion rate on the IEG response to cocaine in the striatum may involve corticostriatal glutamate inputs. First, cocaine increased neuronal activation in the mPFC when it was delivered over $5 \mathrm{sec}$ but not when it was given over 25 or $100 \mathrm{sec}$. Second, infusions over $5 \mathrm{sec}$ significantly increased c-fos expression in Enk + cells within the striatum, whereas 
slower infusions did not. Previous work has shown that stimulation of the cortex, either by release of GABAergic inhibition (Berretta et al., 1997) or electrical microstimulation (Parthasarathy and Graybiel, 1997), elicits c-Fos preferentially in Enk + cells, and the transection of corticostriatal fibers selectively reduces amphetamine-evoked c-fos mRNA expression in Enk + cells (S. M. Ferguson and T. E. Robinson, unpublished observations). It is also relevant that the integrity of the $\mathrm{MPFC}$ is required for the induction of behavioral sensitization to cocaine (Tzschentke and Schmidt, 1998; Li et al., 1999). Therefore, the rapid administration of cocaine may promote cortical activation, which in turn may enhance glutamatergic transmission in the striatum, which contributes to greater IEG expression in this region (especially in Enk + cells), and perhaps greater sensitization.

In conclusion, our findings demonstrate that small differences in the rate at which cocaine is administered result in large differences in its ability to alter IEG expression, especially in the mesocorticolimbic system, and produce one form of neurobehavioral plasticity thought to contribute to addiction. Therefore, we suggest that rapidly administered drugs may increase susceptibility to addiction not necessarily because they are more pleasurable or reinforcing, but because they are particularly effective in producing neuroadaptations that promote the compulsive pursuit of drugs, and the enduring vulnerability to relapse, that characterize the addicted state (Robinson and Berridge, 2003).

\section{References}

Abreu ME, Bigelow GE, Fleisher L, Walsh SL (2001) Effect of intravenous injection speed on responses to cocaine and hydromorphone in humans. Psychopharmacology (Berl) 154:76-84.

Balster RL, Schuster CR (1973) Fixed-interval schedule of cocaine reinforcement: effect of dose and infusion duration. J Exp Anal Behav 20:119-129.

Benoit-Marand M, Jaber M, Gonon F (2000) Release and elimination of dopamine in vivo in mice lacking the dopamine transporter: functional consequences. Eur J Neurosci 12:2985-2992.

Berretta S, Robertson HA, Graybiel AM (1992) Dopamine and glutamate agonists stimulate neuron-specific expression of Fos-like protein in the striatum. J Neurophysiol 68:767-777.

Berretta S, Parthasarathy HB, Graybiel AM (1997) Local release of GABAergic inhibition in the motor cortex induces immediate-early gene expression in indirect pathway neurons of the striatum. J Neurosci 17:4752-4763.

Cenci MA, Campbell K, Wictorin K, Bjorklund A (1992) Striatal c-fos induction by cocaine or apomorphine occurs preferentially in output neurons projecting to the substantia nigra in the rat. Eur J Neurosci 4:376-380

Crombag HS, Badiani A, Robinson TE (1996) Signalled versus unsignalled intravenous amphetamine: large differences in the acute psychomotor response and sensitization. Brain Res 722:227-231.

Crombag HS, Ferrario C, Myc PP, Robinson TE (2003) The rate of intravenous drug infusion does not affect psychomotor stimulant-taking or seeking. Behav Pharmacol 14:S56-S56.

Cullinan WE, Herman JP, Battaglia DF, Akil H, Watson SJ (1995) Pattern and time course of immediate early gene expression in rat brain following acute stress. Neuroscience 64:477-505.

Curran EJ, Watson SJ (1995) Dopamine receptor mRNA expression patterns by opioid peptide cells in the nucleus accumbens of the rat: a double in situ hybridization study. J Comp Neurol 361:57-76.

de Wit H, Dudish S, Ambre J (1993) Subjective and behavioral effects of diazepam depend on its rate of onset. Psychopharmacology 112:324-330.

Dugast C, Suaud-Chagny MF, Gonon F (1994) Continuous in vivo monitoring of evoked dopamine release in the rat nucleus accumbens by amperometry. Neuroscience 62:647-654.

Ferguson SM, Thomas MJ, Robinson TE (2004) Morphine-induced c-fos mRNA expression in striatofugal circuits: modulation by dose, environmental context and drug history. Neuropsychopharmacology, in press.

Fischman MW, Schuster CR (1984) Injection duration of cocaine in humans. Fed Proc 43:570.
Fosnaugh JS, Bhat RV, Yamagata K, Worley PF, Baraban JM (1995) Activation of arc, a putative "effector" immediate early gene, by cocaine in rat brain. J Neurochem 64:2377-2380.

Garris PA, Ciolkowski EL, Pastore P, Wightman RM (1994) Efflux of dopamine from the synaptic cleft in the nucleus accumbens of the rat brain. J Neurosci 14:6084-6093.

Garris PA, Budygin EA, Phillips PE, Venton BJ, Robinson DL, Bergstrom BP, Rebec GV, Wightman RM (2003) A role for presynaptic mechanisms in the actions of nomifensine and haloperidol. Neuroscience 118:819-829.

Gerfen CR (1992) The neostriatal mosaic: multiple levels of compartmental organization. Trends Neurosci 15:133-139.

Gossop M, Griffiths P, Powis B, Strang J (1992) Severity of dependence and route of administration of heroin, cocaine and amphetamines. Br J Addict 87:1527-1536.

Gossop M, Griffiths P, Powis B, Strang J (1994) Cocaine: patterns of use, route of administration, and severity of dependence. Br J Psychiatry 164:660-664.

Hatsukami DK, Fischman MW (1996) Crack cocaine and cocaine hydrochloride. Are the differences myth or reality? JAMA 276:1580-1588.

Hyman SE, Malenka RC (2001) Addiction and the brain: the neurobiology of compulsion and its persistence. Nat Rev Neurosci 2:695-703.

Jentsch JD, Taylor JR (1999) Impulsivity resulting from frontostriatal dysfunction in drug abuse: implications for the control of behavior by reward-related stimuli. Psychopharmacology 146:373-390.

Kato S, Wakasa Y, Yanagita T (1987) Relationship between minimum reinforcing doses and injection speed in cocaine and pentobarbital selfadministration in crab-eating monkeys. Pharmacol Biochem Behav 28:407-410.

Kiyatkin EA, Kiyatkin DE, Rebec GV (2000) Phasic inhibition of dopamine uptake in nucleus accumbens induced by intravenous cocaine in freely behaving rats. Neuroscience 98:729-741.

Kollins SH, Rush CR, Pazzaglia PJ, Ali JA (1998) Comparison of acute behavioral effects of sustained-release and immediate-release methylphenidate. Exp Clin Psychopharmacol 6:367-374.

Li Y, Hu XT, Berney TG, Vartanian AJ, Stine CD, Wolf ME, White FJ (1999) Both glutamate receptor antagonists and prefrontal cortex lesions prevent induction of cocaine sensitization and associated neuroadaptations. Synapse 34:169-180.

McFarlane DK, Martonyi BJ, Robinson TE (1992) An inexpensive automated system for the measurement of rotational behavior in small animals. Behav Res Methods Inst Comput 24:414-419.

Michael DJ, Wightman RM (1999) Electrochemical monitoring of biogenic amine neurotransmission in real time. J Pharm Biomed Anal 19:33-46.

Nestler EJ (2001) Molecular basis of long-term plasticity underlying addiction. Nat Rev Neurosci 2:119-128.

Panlilio LV, Goldberg SR, Gilman JP, Jufer R, Cone EJ, Schindler CW (1998) Effects of delivery rate and non-contingent infusion of cocaine on cocaine self-administration in rhesus monkeys. Psychopharmacology (Berl) 137:253-258.

Parthasarathy HB, Graybiel AM (1997) Cortically driven immediate-early gene expression reflects modular influence of sensorimotor cortex on identified striatal neurons in the squirrel monkey. J Neurosci 17:2477-2491.

Paxinos G, Watson C (1997) The rat brain in stereotaxic coordinates, Compact Ed 3. New York: Academic.

Piazza PV, Deroche V, Rouge-Pont F, Le Moal M (1998) Behavioral and biological factors associated with individual vulnerability to psychostimulant abuse. NIDA Res Monogr 169:105-133.

Pickens R, Dougherty J, Thompson T (1969) Effects of volume and duration of infusion on cocaine reinforcement with concurrent activity recording. In: Minutes of the Meeting of the Committee on Problems of Drug Dependence, NAS-NRC, pp 5805-5811. Washington, DC: NAS-NRC.

Porrino LJ (1993) Functional consequences of acute cocaine treatment depend on route of administration. Psychopharmacology 112:343-351.

Robinson TE, Berridge KC (1993) The neural basis of drug craving: an incentive-sensitization theory of addiction. Brain Res Brain Res Rev 18:247-291.

Robinson TE, Berridge KC (2003) Addiction. Annu Rev Psychol 54:25-53. Samaha AN, Li Y, Robinson TE (2002) The rate of intravenous cocaine administration determines susceptibility to sensitization. J Neurosci 22:3244-3250.

Suaud-Chagny MF, Dugast C, Chergui K, Msghina M, Gonon F (1995) Up- 
take of dopamine released by impulse flow in the rat mesolimbic and striatal systems in vivo. J Neurochem 65:2603-2611.

Torres G, Rivier C (1993) Cocaine-induced expression of striatal c-fos in the rat is inhibited by NMDA receptor antagonists. Brain Res Bull 30:173-176.

Tzschentke TM, Schmidt WJ (1998) The development of cocaine-induced behavioral sensitization is affected by discrete quinolinic acid lesions of the prelimbic medial prefrontal cortex. Brain Res 795:71-76.

Uslaner J, Badiani A, Norton CS, Day HE, Watson SJ, Akil H, Robinson TE (2001) Amphetamine and cocaine induce different patterns of c-fos mRNA expression in the striatum and subthalamic nucleus depending on environmental context. Eur J Neurosci 13:1977-1983.

Uslaner JM, Crombag HS, Ferguson SM, Robinson TE (2003a) Cocaineinduced psychomotor activity is associated with its ability to induce c-fos mRNA expression in the subthalamic nucleus: effects of dose and repeated treatment. Eur J Neurosci 17:2180-2186.

Uslaner JM, Norton CS, Watson SJ, Akil H, Robinson TE (2003b) Amphetamine-induced c-fos mRNA expression in the caudate-putamen and subthalamic nucleus: interactions between dose, environment, and neuronal phenotype. J Neurochem 85:105-114.

Venton BJ, Zhang H, Garris PA, Phillips PE, Sulzer D, Wightman RM (2003) Real-time decoding of dopamine concentration changes in the caudateputamen during tonic and phasic firing. J Neurochem 87:1284-1295.

Weeks JR (1972) Long-term intravenous infusions. In: Methods in psychobiology (Meyers RD, ed), pp 155-168. London: Academic.

Willuhn I, Sun W, Steiner H (2003) Topography of cocaine-induced gene regulation in the rat striatum: relationship to cortical inputs and role of behavioural context. Eur J Neurosci 17:1053-1066.

Winger G, Hofmann FG, Woods JH (1992) A handbook on drug and alcohol abuse: the biomedical aspects, Ed 3. New York: Oxford UP.

Wise RA, Bozarth MA (1987) A psychomotor stimulant theory of addiction. Psychol Rev 94:469-492.

Young ST, Porrino LJ, Iadarola MJ (1991) Cocaine induces striatal c-fosimmunoreactive proteins via dopaminergic D1 receptors. Proc Natl Acad Sci USA 88:1291-1295. 